\title{
Study of Comparative Aspects Pertaining to Milking Management and Marketing Practices in Specialized Dairy Farms of North and South Gujarat Regions
}

\author{
D. N. Gadhavi ${ }^{1}$, L. M. Sorathiya ${ }^{2}$ and A. L. Rathva ${ }^{1}$ \\ ${ }^{1}$ Department of Livestock Production and Management, Vanbandhu College of \\ Veterinary Science and Animal Husbandry \\ ${ }^{2} P G$ Institute of Veterinary Education and Research, Kamdhenu University, \\ Rajpur (Nava), Himatnagar, Gujarat, India \\ *Corresponding author
}

\section{A B S T R A C T}

\section{Keywords}

Automatic shower system, Herringbone milking parlour, On line milk marketing

\section{Article Info}

Accepted:

12 March 2020

Available Online:

10 April 2020
A study was carried out to compare the feeding management practices of specialized dairy farms of north and south Gujarat. The data were collected from each ten specialized dairy farm each from north and south Gujarat. Analyzed data revealed that Machine milking was used by more $(35 \%)$ dairy farms while, advanced parlour system was used by around 20 per cent dairy farms. Significantly higher $(70 \%)$ numbers of the dairy farms of north region were preferred machine milking. Majority (70\%) of dairy farms were using potassium permanganate as a dipping solution while in $30 \%$ of the dairy farms were using iodine as a teat dipping solution. Around 25 per cent dairy farms were using automatic shower system to wash their animals before milking. Majority of the dairy farms (80\%) were selling only milk and few dairy farms $(20 \%)$ were selling milk and its value added products. It was slightly higher in south region as compare to north region. Few dairy farms $(20 \%)$ were using their waste by selling it in the form of prepared manure in both the regions. Proportion of marketing milk to co-operative sector was higher $(55 \%)$ while, few dairy farms $(5 \%)$ were selling their milk through online marketing platform. Significantly higher $(80 \%)$ of the dairy farms of north region were selling their milk directly to co-operative sector.

\section{Introduction}

Good management practices especially in milking and healthcare is important for quality milk production. Quality milk production is future of advanced dairy farms who want to sale his milk by his own brand. It is also having public health importance. Milking is an art which needs skill, experience and sincerity among milkers and managers. The milking must be conducted at regular intervals, quickly, cleanly, gently, quietly and completely by considering protocols laid down (Kamboj et al., 2014). 
Milking barn should remain clean and it should be disinfected regularly. Washing of animals facilitates clean milk production. Cleaning and disinfection of milking area as well as udder area was having good adoption (Yankam and Bhanotra, 2018). Marketing of milk is directly related with farm profitability.

Traditionally, based on USDA estimate from 2007-08 to 2011-12 the fluid milk marketing channels in India revealed that $48 \%$ of milk produced was not traded/consumed by households, $36 \%$ was traded by small scale venders, $8 \%$ by cooperatives, $7 \%$ by private organized sectors. It clearly indicates that marketing strategy for milk and its products is key point for success of dairy farm. Now a day many large milk producers claims that their milk is "untouched milk" means they are not touching milk right from production to marketing. They are milking animals by machine and process themselves in such a way that milk is reaching to consumers untouched. Maintenance of herd health by vaccination, deworming, etc., is also having importance.

Now a day many areas in Gujarat having good numbers of specialized farms. Many such farm owners are claims themselves as most profitable farms, whereas, some are in closed due no nonpayment of installment to banks against loan. Therefore, it needs systemic study. Among 33 districts of Gujarat, from north Gujarat, Banaskantha and Sabarkantha districts and from south Gujarat, Bharuch, Surat and Navsari districts are known for milk production, specialized dairy farms adopting modern technologies, and established cooperative milk producers unions.

The agro-climatic condition in both regions are quite different as north Gujarat has semiarid to dry climate with less rainfall, whereas south Gujarat falls under medium to heavy rainfall zone. Specialized dairy farming in both regions needs to be understood considering its importance. However, not much work has been carried out about comparative aspects of prevailing milking and marketing management practices of dairy farmers from these regions, hence, present study was carried out.

\section{Materials and Methods}

The dairy farms which contributed more than 50 per cent in total income of farm owners were considered specialized dairy farms. A list was prepared for all such farms in selected districts i.e. Surat, Navsari, Bharuch, Banaskantha and Sabarkantha which were having minimum 40 heads of either white cattle or buffalo. Sabarkantha districts were having 25 farms whereas Banaskantha has such 5 farms. From this both district 10 farms were selected randomly as a sample of north Gujarat.

To study specialized farms in heavy to medium heavy rainfall zone, 10 specialized dairy farms were selected randomly from Surat, Bharuch and Navsari districts of south Gujarat from available 31 farms. The information pertaining to prevailing management practices was collected by interviewing respondents by using questionnaire method. Collected data were tabulated, analyzed using frequency and percentages and compared by chi-square test following Snedecor and Cochran (1994).

\section{Results and Discussion}

\section{Milking management practices}

The information regarding milking management practices are presented in Table 1. It indicated that machine milking was used by more $(35 \%)$ dairy farm followed by hand milking $(30 \%)$, hand + machine $(15 \%)$ and advanced parlour system (15\%). Significantly higher $(70 \%)$ numbers of the dairy farms of 
north region were preferred hand milking. It indicated that machine milking method was more popular in south region. However, 20 per cent of dairy farms from both the regions one from north and another one from south were surprisingly possessed Herringbone milking parlour that was very convenient and reliable method for milking in such type of large herd sized specialized dairy farm because it can able to milked large number of animal at one time.

This results are higher than the result of Vranda et al., (2017) who reported that only $8.33 \%$ dairy farmers were using milking machine because former study was conducted on commercial buffalo dairy farms and mostly buffalo dairy farmers of such farm were used to hand milking while, present study was conducted on highly specialized dairy farms of buffalo along with cattle. It was observed that in majority $(70 \%)$ of dairy farms teat dipping were done by using potassium permanganate as a dipping solution while in $30 \%$ of the dairy farms used iodine as a teat dipping solution. It was statistically almost similar for both the regions. As teat dipping is essential to control the spread of mastitis organisms during milking consideration about dipping solution is very important because during milking, it is possible that contamination can enter the teat dip cup.

This will be easily seen in lighter coloured solutions such as chlorhexidine or hypochlorite but it may be more difficult to see in iodine or dark coloured solutions. If contaminated, the solution should be discarded, and the cup cleaned and refilled (Peter, 2003). This result is higher than the result of Kaur et al., (2017) who reported that only 12.50 per cent dairy farmers were using potassium permanganate as a dipping solution. Results of present study indicated that all the dairy farms were followed the practice of teat dipping. However, only few dairy farms (30\%) were not aware regarding the use of better dipping solution. These results are not similar with the results of Bafanda et al., (2018) and Sabapara et al., (2016).

As they were reported only 1 per cent of dairy farmers were followed the practice teat dipping. It was very higher in present study also regarding use of dipping solution result of present study was totally opposite to the result of Bafanda et al., (2018) who reported that not any single dairy farmers were using potassium permanganate solution as a dipping solution might be due to associated with location of farms. Present study was on specialized dairy farms whereas former study was from rural farms.

Majority $(75 \%)$ of the dairy farms were washing their animals before milking by manually. However, interestingly 25 per cent dairy farms were using automatic shower system to wash their animals before milking. This finding is comparatively higher to the result of Kishore et al., (2013) who reported that about 15.68 per cent of dairy farmers were washing their animals before milking.

This might be due to present study was conducted on specialized dairy farms that are highly aware about washing with water before milking of animal is very important to make an animal clean also it have good effects on body temperature before milking of animal ultimately it ensure the clean and high milk production in compare to this small dairy farmers of former study were less aware about it.

Regarding place of milking it was found that half of the dairy farms were keeping their animals at same place while, remained half of the dairy farms were keeping at separate clean and dry place. In contrary to this Sabapara et al., (2016) reported that all the dairy farms milking their animals at a same place. It was 
statistically similar for both the region.

However, number of dairy farms were keeping their animals at separate clean place were slightly higher $(60 \%)$ in north region as compare to south region $(40 \%)$. This result might be due to lack of space for milking in separate area in south region. Data presented in Table 1 indicated that in most of the dairy farms test of mastitis were done regularly by visual examination.

However, in few dairy farms it was done by laboratory method either in own or other government institute or co-operative laboratory. However, test of mastitis was done by dairy farms regularly in both the region. This finding is contrary to Tewari et al., (2018) who reported that majority of the farmers $(60 \%)$ checked their animals for mastitis only when required. It indicates in present study that dairy farms were very aware and conscious about retrogressive effect of mastitis disease on economic output as well as production of animal.

\section{Milk marketing practices}

Data about milk marketing practice are presented in Table 2 which depicted that majority of the dairy farms $(80 \%)$ were selling only milk while few dairy farms $(20 \%)$ were selling milk and its value added products like ghee, butter, paneer, lassi and sweets etc. It was statistically similar for both the region.

However, selling of milk and its valuable products were slightly higher in south region as compare to north region because most if the dairy farms of south region were selling their milk as well as by making valuable products from it in private sector for their better marketing as well as good economic output that was alike to north region where they are selling their milk directly in cooperative dairy sector. This finding is encouraged by Upadhyay and Desai (2011) who reported that half of the dairy farm women $(50.83 \%)$ were preparing milk products.

Majority $(80 \%)$ of the dairy farms were using the dairy farm waste in their own agriculture land. However, few dairy farms $(20 \%)$ were using their waste by selling it in the form of prepared manure in both the regions. It was statistically similar in both the region.

These findings are higher than the result of Birthal et al., (2008) who reported that regarding the use of dairy farms waste only 2.7 per cent dairy farmers sold manure and 4.7 per cent use dung as fuel. Result of present study indicated that use of dung or farm waste in their agriculture land was higher for both regions.

However, few dairy farms were selling it in the form of prepared or organic manure to get a maximum economic output. It might be due to owners of specialized dairy farm are highly aware and had higher infrastructure facilities for utilizing the farm waste to get maximum economic output. Data of milk and its valuable product disposal pattern presented in Table 2 clearly indicates that the proportion of marketing milk to co-operative sector was higher $(55 \%)$ followed by door to door selling directly to consumers by own vehicle (20\%), directly to private dairy stall $(15 \%)$, directly from own dairy stall (5\%); whereas, few dairy farms $(5 \%)$ were selling their milk through online marketing platform. Present result is supported by Malsawmdawngliana and Rahman (2016). Kaur et al., (2014) also reported that proportion of selling milk to Cooperative sector was comparatively much higher. 
Table.1 Distribution of the dairy farms of north and south Gujarat according to milking practices followed

\begin{tabular}{|c|c|c|c|c|c|c|c|c|c|}
\hline \multirow{2}{*}{$\begin{array}{l}\text { Sr. } \\
\text { no. }\end{array}$} & \multirow[t]{2}{*}{ Practices } & \multicolumn{2}{|c|}{ North } & \multicolumn{2}{|c|}{ South } & \multicolumn{2}{|c|}{ Over all } & \multicolumn{2}{|c|}{ Chi square } \\
\hline & & $\mathbf{n}$ & $\%$ & $\mathbf{n}$ & $\%$ & $\mathbf{n}$ & $\%$ & $\mathbf{F}$ & $\mathbf{P}$ \\
\hline \multirow[t]{5}{*}{1} & Method of milking & & & & & & & & \\
\hline & Hand milking & 00 & 00 & 6 & 60 & 6 & 30 & \multirow[t]{4}{*}{13.33} & \multirow[t]{4}{*}{$0.00^{*}$} \\
\hline & Machine & 7 & 70 & 00 & 00 & 7 & 35 & & \\
\hline & $\begin{array}{l}\text { Machine milking together with hand } \\
\text { milking }\end{array}$ & 1 & 10 & 2 & 20 & 3 & 15 & & \\
\hline & Milking parlor & 2 & 20 & 2 & 20 & 4 & 20 & & \\
\hline \multirow[t]{3}{*}{2} & Teat dipping by using & & & & & & & & \\
\hline & $\mathrm{KMnO}_{4}$ as a dipping solution & 6 & 60 & 8 & 80 & 14 & 70 & \multirow[t]{2}{*}{0.95} & \multirow[t]{2}{*}{0.32} \\
\hline & Iodine as a dipping solution & 4 & 40 & 2 & 20 & 6 & 30 & & \\
\hline \multirow[t]{3}{*}{3} & Cleaning of animal before milking by & & & & & & & & \\
\hline & Automatic shower bathing & 3 & 30 & 2 & 20 & 5 & 25 & \multirow[t]{2}{*}{0.26} & \multirow[t]{2}{*}{0.60} \\
\hline & Manually & 7 & 70 & 8 & 80 & 15 & 75 & & \\
\hline \multirow[t]{3}{*}{4} & Milking place & & & & & & & & \\
\hline & Same place & 4 & 40 & 6 & 60 & 10 & 50 & \multirow[t]{2}{*}{0.80} & \multirow[t]{2}{*}{0.37} \\
\hline & Separate place & 6 & 60 & 4 & 40 & 10 & 50 & & \\
\hline \multirow[t]{3}{*}{5} & Test of mastitis by which way & & & & & & & & \\
\hline & Visual examination & 5 & 50 & 8 & 80 & 13 & 65 & \multirow[t]{2}{*}{1.97} & \multirow[t]{2}{*}{0.16} \\
\hline & Laboratory test & 5 & 50 & 2 & 20 & 7 & 35 & & \\
\hline
\end{tabular}

Table.2 Distribution of the dairy farms of north and south Gujarat according to milk marketing practices followed

\begin{tabular}{|c|c|c|c|c|c|c|c|c|c|}
\hline \multirow{2}{*}{$\begin{array}{l}\text { Sr. } \\
\text { no. }\end{array}$} & \multirow[t]{2}{*}{ Practices } & \multicolumn{2}{|c|}{ North } & \multicolumn{2}{|c|}{ South } & \multicolumn{2}{|c|}{ Over all } & \multicolumn{2}{|c|}{ Chi square } \\
\hline & & $\mathbf{n}$ & $\%$ & $\mathbf{n}$ & $\%$ & $\mathbf{n}$ & $\%$ & $\mathbf{F}$ & $\mathbf{P}$ \\
\hline \multirow[t]{3}{*}{1} & Pattern of milk selling & & & & & & & \multirow{3}{*}{1.25} & \multirow[t]{3}{*}{0.26} \\
\hline & Only milk & 9 & 90 & 7 & 70 & 16 & 80 & & \\
\hline & Milk and its value added products & 1 & 10 & 3 & 30 & 4 & 20 & & \\
\hline \multirow[t]{3}{*}{2} & Pattern of waste utilization & & & & & & & \multirow{3}{*}{0.00} & \multirow{3}{*}{1.00} \\
\hline & Directly use in self-farming & 8 & 80 & 8 & 80 & 16 & 80 & & \\
\hline & Sale it in the form of prepared manure & 2 & 20 & 2 & 20 & 4 & 20 & & \\
\hline \multirow[t]{6}{*}{3} & Marketing way of milk and its valuabl & odu & s sel & & & & & \multirow[t]{6}{*}{8.27} & \multirow[t]{6}{*}{0.08} \\
\hline & Door to door service by own vehicle & 1 & 10 & 3 & 30 & 4 & 20 & & \\
\hline & Direct sell from own dairy stall & 00 & 00 & 1 & 10 & 1 & 5 & & \\
\hline & Direct Sell to other party dairy stall & 00 & 00 & 3 & 30 & 3 & 15 & & \\
\hline & $\begin{array}{l}\text { Online marketing along with selling } \\
\text { from own dairy stall }\end{array}$ & 1 & 10 & 00 & 00 & 1 & 5 & & \\
\hline & Sell in Cooperative dairy sector & 8 & 80 & 3 & 30 & 11 & 55 & & \\
\hline
\end{tabular}


These findings are statistically not similar between two regions because majority (80\%) of the dairy farms were selling their milk directly to co-operative sector reason due to benefits given by co-operative sector in the form of various subsidies and door service of medical and milk transport facilities also they were not interested to took a headache of marketing for huge quantity of milk on their heads.

Beside of these things one dairy farm of north Gujarat had very well established own private market (owned dairy stall and online platform) and for its milk and value added products because of its unique strategy on clean milk production.

However, this result is completely opposite in south region where, only 30 per cent of dairy farms were selling their milk directly to cooperative sector because they were believing that by the selling of their buffalo milk in dairy they were not getting price as per their requirement. Further, demand of raw buffalo milk is higher among consumers of south region.

From the above result it can conclude that marketing pattern of north and south Gujarat is completely opposite as majority of the specialized dairy farms of north Gujarat are very well associated with organized cooperative sector they are not interested in private selling of milk and making of value added products of milk because they don't want to take further headache of marketing.

On the other hand, majority of the dairy farms of south region are more interested towards the private selling of milk and its valuable products because of high feeding cost and cost of milk production in south region dairy farms owners' belived that they can get more price and good economic returns by private selling of milk.

\section{Acknowledgements}

Authors thank the Dean, College of Veterinary Science and Animal husbandry and the University authorities, Navsari Agricultural University, Navsari for the facilities provided for this research work.

\section{References}

Bafanda, R. A., Nanda, R., Choudhary, F., Choudhary, M. S. and Shehjar, F. 2018. Clean Milk Production Practices Adopted by the Dairy Farmers of RS Pura in Jammu District. Asian Journal of Agricultural Extension, Economics \& Sociology, 1-10.

Birthal, P. S., Jha, A. K., Tiongco, M. M. and Narrod, C. 2008. Improving farm-tomarket linkages through contract farming: a case study of smallholder dairying in India. Intl Food Policy Res Inst.

doi:

https://doi.org/10.20546/ijcmas.2018.70 4.405

Kamboj, M.L., Prasad, S., Oberoi, P.S., Manimaran, A., Lathwal, S.S. and Gupta, K. 2014. National Code of Practices for Management of Dairy Animals in India. Developed by: ICARNational Dairy Research Institute, Karnal.

Kaur, M., Sekhon, M. K. and Dhawan, V. 2014. Marketable surplus, pattern and constraints faced by smallholder dairy farmer in Punjab. Economic Affairs, 59(4): 641.

Kaur, S., Verma, H. K., Singh, J., Dash, S. K. and Kansal, S. K. 2017. Knowledge level of women dairy farmers about various farming practices in border area of Punjab. Journal of Animal Research, 7(6): 1051-1059.

Kishore, K., Mahender, M. and Harikrishna, C. 2013. A study on buffalo 
management practices in khammam district of Andhra Pradesh. Buffalo bulletin, 32(2): 97-107.

Malsawmdawngliana, R. and Rahman, S. 2016. Management practices followed by the dairy farmers of Mizoram, India. Journal of Livestock Science, 7: 220-225.

Sabapara, G. P., Padheriya, Y. D. and Kharadi, V. B. 2016. A field survey of feeding and breeding practices at peri urban buffalo farms of Surat city of Gujarat. Journal of Animal Research, 6(5): 933-939.

Snedecor, G. W. and Cochran, W.G. 1994. Statistical Methods. 8th edn. Oxford and IBH Publishing Co., New Delhi.

Tewari, H., Kumar, S., Rath, R. and Tyagi, K. 2018. Existing housing and breeding management practices adopted by dairy farmers in Tarai region of Uttarakhand, India. Indian Journal of Animal Research, 52(3): 449-453.

Upadhyay, S., and Desai, C. P. 2011. Participation of farm women in animal husbandry in Anand District of Gujarat. J. Community Mobilization and Sustainable Development, 6(2): 117121.

Vranda, R., Satyanarayan, K., Jagadeeswary, V. and Shilpa, J. 2017. Milking and marketing practices of buffalo farmers in Karnataka. Indian Journal of Animal Health, 56(1): 43-52.

Yankam, S. R. and Bhanotra, A. 2018. Health Management and Clean Milk Production Practices Followed by Dairy Farmers of Nanded District of Maharashtra, India. Int. J. Curr. Microbiol. App. Sci. 7(04): 3592 - 3598.

\section{How to cite this article:}

Gadhavi, D. N., L. M. Sorathiya and Rathva, A. L. 2020. Study of Comparative Aspects Pertaining to Milking Management and Marketing Practices in Specialized Dairy Farms of North and South Gujarat Regions. Int.J.Curr.Microbiol.App.Sci. 9(04): 1694-1700. doi: https://doi.org/10.20546/ijcmas.2020.904.198 